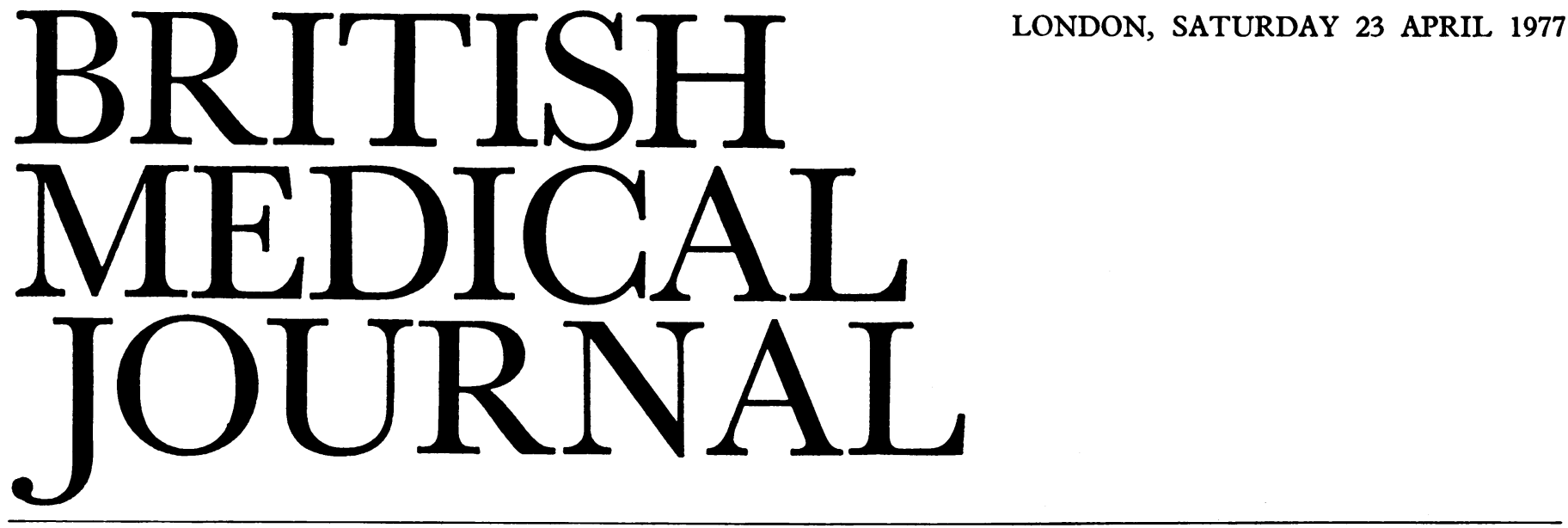

\title{
Speed limits and the public health
}

One of the most important consequences of the energy crisis was the imposition of speed restrictions on our roads of a severity which would have been regarded as politically unacceptable if they had been imposed in the interests of preventing road accidents instead of conserving fuel. Although factors such as an increase in wearing safety belts and improvements in vehicle design may have played a part, undoubtedly it was speed restrictions which were largely responsible for the fall between 1973 and 1975 of $8 \%$ in road accident casualties and, more important for public health, of $14 \%$ in those killed or seriously injured. ${ }^{1}$ The restrictions were introduced in two stages with a period of relaxation in between. On 19 November 1973 drivers were asked not to exceed $50 \mathrm{mph}(80 \mathrm{kph})$ and from 8 December this limit was imposed compulsorily on all roads not already subject to a lower limit. The $70 \mathrm{mph}$ (113 $\mathrm{kph}$ ) limit was restored on 29 March 1974 on motorways, and on 8 May on other roads. The next December speed limits of $50 \mathrm{mph}$ were imposed on single carriageways, and $60 \mathrm{mph}$ $(97 \mathrm{kph})$ on dual carriageways, not previously subject to a lower limit, leaving motorways with the old $70 \mathrm{mph}$ limit, and this remains the position today.

A detailed statistical analysis has now been published of the accident rates between November 1973 and July $1975 .^{2}$ By taking the accident rates per million vehicle kilometres the authors have excluded factors which may have influenced -traffic volume during this period, such as the three-day week, car sharing, and the rail dispute-leaving those factors which influence driver behaviour and exposure to risk, of which speed restrictions and cuts in street lighting were the most important.

Although motorways are relatively safe, those accidents which occur on them carry a higher risk of death or serious injury. The $70 \mathrm{mph}$ limit on motorways was originally introduced some 10 years ago and the effect did not pass unnoticed by the staffs of accident and emergency departments adjacent to the M1. The temporary imposition of a $50 \mathrm{mph}$ limit in December 1973 had a similar effect. Census-taking on the M3 and M4 during a preceding period had shown that the mean speed of drivers was $70 \mathrm{mph}$, with $49 \%$ exceeding the limit. By mid-December 1973 the mean speed had been reduced to $54 \mathrm{mph}(87 \mathrm{kph})$ and only $1 \%$ of drivers were exceeding $70 \mathrm{mph}$. By September 1974, a few months after the $50 \mathrm{mph}$ limit had been lifted, the mean speed was back to $70 \mathrm{mph}$ and half the drivers were exceeding it. During the period the $50 \mathrm{mph}$ limit was in operation the authors were able to find a "highly significant" reduction $(P>0.01)$ in the injury accident rate on motorways, which reverted to "normal" soon after the limit was lifted. On all-purpose roads they also found a "highly significant" reduction in the accident rate, which reverted to "normal" shortly before the limit was lifted. The consequence of stage 2, which was introduced in December 1974 on all-purpose roads, was an immediate drop in the number of drivers exceeding $50 \mathrm{mph}$ on single carriageway A class roads from $26 \%$ to $13 \%$, but this had reverted to $20 \%$ within three months. "Significant" reductions in the accident rates on all-purpose roads in non-built-up areas were achieved each month up to the end of February. The authors conclude that stage 2 had some effect on driving speeds and that this led to reduced accident rates, although the increase in the price of petrol (which had doubled in the past 12 months) may have played a part.

This is the background against which the Minister of Transport has announced his decision to raise the limits on single carriageways to $60 \mathrm{mph}$ and on dual carriageways to $70 \mathrm{mph}$, having consulted over 50 organisations, none of them medical. The exchange which took place in Parliament ${ }^{3}$ after this announcement was largely congratulatory, one member inquiring eagerly when the $70 \mathrm{mph}$ limit was to be lifted on motorways. Only one member, at the end of the debate, inquired whether the Minister agreed that speed was a contributory factor to road accidents and that more people would be killed or injured as a result of his decision. The Minister agreed. "We want to save life, but we like driving fast," he explained, adding, "It is dangerous in some respects, but that is life." It is fairly characteristic of the attitude of public health authorities to road safety that they should have taken no steps to influence a political decision which can strongly influence mortality and morbidity. The beneficial effect of speed limits on injury-producing road accidents has been apparent ever since Mr Hore-Belisha (as he then was) introduced a $30 \mathrm{mph}$ (48 kph) limit in built-up areas as part of a package of road safety measures in the Road Traffic Act of 1934-which included introducing driving tests and pedestrian crossings. The result was a $15 \%$ reduction in fatal accidents, and the previous number of deaths on the roads was not to be exceeded in peacetime until 1964, by which time traffic had increased fourfold.

Drivers are subject to many restrictions, the reasons for which are not always obvious to them. The indiscriminate imposition of the $30 \mathrm{mph}$ limit led to the controversial " 85 percentile" rule, under which local authorities can raise the 
speed limit on certain roads in built-up areas in cases where surveys show that $85 \%$ or more of drivers are exceeding the limit. It is claimed that this results in little change in the distribution of vehicle speeds, and that in some cases accident rates have been reduced. ${ }^{4}$ It is further claimed that drivers will not abuse what they regard as a realistic limit, and that, if the frustrations of too low a limit are removed, driver behaviour may change in a manner conducive to accident reduction. These claims do not, of course, take into account the fact that on many urban roads driving speeds are restricted by the sheer volume of traffic as much as by speed limits. Even if these claims are justified, it does not follow, as the Minister has tried to argue ${ }^{5}$ in support of his decision to relax the existing limits, that similar considerations will apply on rural roads, where the risk of serious injury is much greater. The Minister has pointed out that compliance with the existing limits fell between 1975 and 1976 and that they are difficult to enforce to the extent needed to maintain respect for road traffic law. What he did not go on to say is that the provisional figures for 1976 show a $4 \frac{1}{2} \%$ increase in casualties over 1975 with a $10 \%$ increase in the last quarter. ${ }^{6}$

From the public health point of view it is important to appreciate that the effect of speed restrictions is most definite in those accidents which result in death or serious injury. Experiments on selected stretches of road have shown that repeated stepping up of enforcement rates results in very substantial casualty savings-not only on the selected roads, but on adjacent roads as well. ${ }^{7}$ Speed limits will not be effective unless they are properly enforced. A study in Michigan showed that the chance of being detected while exceeding the limit on one road was only once in 7600 violations. ${ }^{8}$ The results of such low levels of enforcement are that drivers no longer feel any responsibility for observing the limit and merely consider themselves to be unlucky if they are detected.

Public health authorities, who are concerned about the increasing number of victims permanently incapacitated from road accidents, and the medical profession, which has to deal with the consequences, may not be aware of the arguments put forward in support of relaxing speed limits as they were not included in the list of organisations to which the Minister of Transport sent his consultation letter on this important issue. The leading argument appears to be that changes in driving habits such as the more prudent use of the accelerator and brakes, and increasing resort to smaller cars (which reduce protection against injury) have been more effective than speed restrictions in reducing fuel consumption, which is, of course, the reason why they were introduced. If we did the right thing for the wrong reason in 1973, it is all the more important that we should not now do the wrong thing for the right reason.

${ }^{1}$ Department of the Environment, Scottish Development Department and Welsh Office, Road Accidents Great Britain 1975, $\mathrm{p}$ xv. London, HMSO, 1977.

2 Scott, P P, and Barton, A J, The Effects on Road Accident Rates of the Fuel Shortage of November 1973 and Consequent Legislation. TRRL Supplementary Report 236. Crowthorne, Transport and Road Research Laboratory, 1976.

3 Hansard (House of Commons), 6 April 1977, cols 1198-1201.

${ }^{4}$ Sabey, B E, in Epidemiological Effects of Traffic Speed and Speed Limitation, ed E L Nordentoft, J A Wallin, and H V Nielsen, p 185. Odense, Odense University Press, 1975.

5 Hansard (House of Commons), 6 April 1977, cols 519-520.

6 Department of Transport, Road Casualties: Provisional 1976 Figures. Press Notice No 116, 13 April 1977.

7 Munden, J M, An Experiment in Enforcing the $30 \mathrm{mph}$ Limit, RRL Report LR24. Harmondsworth, Road Research Laboratory, 1966.

${ }^{8}$ Organisation for Economic Co-operation and Development. Report of Research Group $(S 6)$ on the Effects of the Enforcement of Legislation on Road User Behaviour and Traffic Accidents. Paris, Organisation for Economic Co-operation and Development, 1974.

\section{Polymyalgia arteritica}

Giant-cell (cranial) arteritis was first described by Horton and his colleagues ${ }^{1}$ at the Mayo Clinic, Rochester, Minnesota, in 1932; polymyalgia rheumatica was first so named by Hugh Barber $^{2}$ of Buxton in 1957, though Kersley ${ }^{3}$ and Bagratuni ${ }^{4}$ had previously described it as a probable variant of rheumatoid arthritis in the elderly. Barber followed up his patients for as long as 10 years and, finding that they did not develop rheumatoid arthritis, suggested the title polymyalgia rheumatica. Since then, arteritis has been shown to be the underlying pathological process in both disorders, and Hamrin and his co-workers ${ }^{56}$ suggested it should be termed polymyalgia arteritica. Patients with symptoms of polymyalgia may develop features of giant cell arteritis and vice versa, and $\mathrm{Hart}^{7}$ among others has emphasised that visual complications occur in both syndromes.

The treatment of both polymyalgia rheumatica and giant cell arteritis is the same-prednisolone or a similar corticosteroid. A low dosage of 6-10 mg prednisolone daily will control morning stiffness and girdle pains in the shoulders and hips very adequately, but it is not enough to prevent visual complications, for which $40-50 \mathrm{mg}$ daily is required. In 1974 Anderson and Bayles ${ }^{8}$ claimed that no patient on this full dosage and with a sedimentation rate restored to normal had been reported as losing her vision, but this remains the crucial hazard-thrombotic obliteration of the central artery of the retina can occur in a few hours at lower dosages. Any patient with the polymyalgia syndrome should therefore be warned to report immediately to her general practitioner any sudden exaggeration or spread of symptoms to affect temples, scalp, or occiput, and particularly any changes in vision, so that corticosteroid dosage can be instantly increased to prevent the blindness which may otherwise occur. A 12-hour delay, or even less, may prove disastrous.

Polymyalgia arteritica will disappear naturally, even if untreated, within four to eight years, and its control is usually assessed by relief of symptoms and the fall in the sedimentation rate. If the patient is symptom free, has no morning stiffness in the girdle joints, feels well, and has a sedimentation rate under $20 \mathrm{~mm}$ in one hour all should be satisfactory, and the daily prednisolone dosage may be reduced very gently-by as little as 0.5 to $1 \mathrm{mg}$ every few weeks or months. A recent case report, ${ }^{9}$ however, has shown that inflammatory arterial disease may persist despite normal sedimentation rates and complete absence of symptoms. Rynes and his colleagues in New York described a 70-year-old woman with typical polymyalgia rheumatica and normal findings on biopsy of the temporal artery who, despite a normal sedimentation rate and complete absence of symptoms, had a return of symptoms on reducing the dosage of prednisone from $5 \mathrm{mg}$ to $4 \mathrm{mg}$ daily. At this time, though the sedimentation rate remained normal $(20 \mathrm{~mm}$ in one hour), she experienced firstly angina of effort and then pains in her temples; her right temporal artery became clinically inflamed; and her temporal artery biopsy showed giant cell arteritis. The symptoms rapidly disappeared on increasing the dose of prednisone to $20 \mathrm{mg}$ daily.

Clearly, inflammatory arterial disease can escape from control without the sedimentation rate becoming truly abnormal; in this particular case the symptoms were more helpful than the results of the laboratory tests. Clinicians should depend more on symptoms and signs than on investigations and be very suspicious of cases, such as this one, where symptoms abate early under treatment. Though some cases of poly- 